\title{
Flow Dependence of Carbon Dioxide Corrosion Using Short Electrodes by Jet Impingement
}

\author{
D. John, ${ }^{,, *}$ B. Kinsella, ${ }^{*}$ S. Bailey, ${ }^{*}$ and R. De Marco*
}

\section{ABSTRACT}

The jet impingement technique is a valuable methodology for the evaluation of carbon dioxide $\left(\mathrm{CO}_{2}\right)$ corrosion and inhibition under high flow velocities. This technique commonly uses short electrodes that remain within a region of the developing diffusion boundary layer induced by the reactively corroding surface. The use of such electrodes has been associated with the poor correlation of corrosion rates determined from field and laboratory measurements by various apparatus. This paper presents an investigation into the flow relationship of the $\mathrm{CO}_{2}$ corrosion mechanism in non-scaling synthetic brine solutions at $30^{\circ} \mathrm{C}$ with a $\mathrm{CO}_{2}$ partial pressure of 1.88 bar. The effect of the developing diffusion boundary layer on the corrosion rate and its dependence on the flow velocity is investigated by jet impingement using dissimilar electrode lengths in the flow direction. It is shown that the measured corrosion rate is dependent on the state of development of the diffusion boundary layer with a relationship that is contrary to the average rate of mass transfer. A more developed diffusion boundary layer exhibits a greater rate of $\mathrm{CO}_{2}$ corrosion at a lower average mass transfer than in a developing diffusion boundary layer with a higher average mass transfer. This phenomenon illustrates an antagonistic effect of the diffusion boundary layer on the mechanism of $\mathrm{CO}_{2}$ corrosion that is likely to strongly influence the correlation of corrosion rates obtained using various laboratory apparatuses and field applications.

KEY WORDS: carbon dioxide corrosion, corrosion, flow dependence, jet impingement, mass-transfer entry length

\section{INTRODUCTION}

The effect of flow velocity on carbon dioxide $\left(\mathrm{CO}_{2}\right)$ corrosion often limits the rate of oil and gas production. The importance of research in this area has seen the development of numerous laboratory techniques based on reproducing critical hydrodynamic parameters. Three renowned techniques used to study flow effects are the rotating cylinder electrode (RCE), jet impingement cell (JIC), and recirculating flow loop (RFL). Application notes and the theory of these techniques is described in NACE publication 5A195. ${ }^{1-2}$

Similitude with the hydrodynamics of pipe flow is often assumed through the correlation of the mass transfer and wall shear stress in laboratory test geometries. ${ }^{3}$ However, various test geometries exhibit unique relationships between the wall shear stress and the mass transfer as illustrated by Equations (1) through (3). ${ }^{4}$ Achieving true similitude in both parameters is very difficult, restricting researchers to the correlation of either the mass transfer or the wall shear stress. Through appropriate sizing of an RCE, Silverman illustrated that both parameters could be reproduced simultaneously. ${ }^{5}$ However, the practical region for hydrodynamic similarity with pipe flow is limited and cannot represent high velocity or conditions of severe turbulence.

$$
\begin{gathered}
\mathrm{k}_{\mathrm{RCE}}=\left(\frac{\tau_{\mathrm{w}}}{\rho \mathrm{U}}\right) \mathrm{Sc}^{-0.644} \\
\mathrm{k}_{\mathrm{JIC}}=3.78\left(\frac{\tau_{\mathrm{w}}}{\rho \mathrm{U}}\right) \mathrm{Sc}^{-0.667}\left(\frac{\mathrm{r}}{\mathrm{D}}\right)^{0.8}
\end{gathered}
$$

\footnotetext{
Submitted for publication March 2008; in revised form, May 2009.

‡ Corresponding author. E-mail: d.john@curtin.edu.au.

Western Australian Corrosion Research Group, Department of
} 


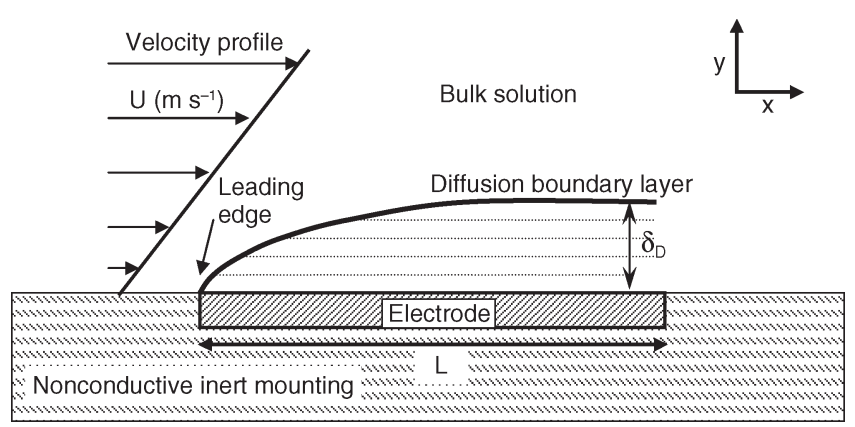

FIGURE 1. Illustration of the development of the diffusion boundary layer with a flowing solution over an active surface.

$$
\mathrm{k}_{\text {Pipe }}=0.0889 \sqrt{\frac{\tau_{\mathrm{w}}}{\rho}} \mathrm{Sc}^{-0.704}
$$

where $\tau_{\mathrm{w}}$ is wall shear stress (Pa), $\rho$ is density $\left(\mathrm{kg} \mathrm{m}^{-3}\right)$, $\mathrm{U}$ is respective linear flow velocity $\left(\mathrm{m} \mathrm{s}^{-1}\right)$, Sc is the Schmidt number, and $\mathrm{k}$ is the mass-transfer coefficient $\left(\mathrm{m} \mathrm{s}^{-1}\right)$ (subscripts represent the relevant test geometry). There are unique terms for the JIC equation, which is valid only in the wall jet region, $3<\mathrm{r} / \mathrm{D}<6$, where $r$ is the radial distance from the center line of the impinging jet $(\mathrm{mm})$ and $\mathrm{D}$ is the jet diameter $(\mathrm{mm})$.

Numerous comparisons of corrosion rates determined by various techniques, based on the correlation of the mass transfer or wall shear stress, often report discrepant conclusions. ${ }^{4,6-12}$ Turgoose, et al., suggested that the poor correlation of corrosion rates determined from the RCE with RFL and JIC measurements is attributable to the mass-transfer entry length (MTEL). ${ }^{13}$ The MTEL is an expression of the developing diffusion boundary layer over small electrodes (Figure 1) that are electrically isolated from the test apparatus by mounting in a nonconductive inert material (e.g., epoxy or plastic). Such electrode designs are used in both the RFL and JIC techniques.

The problem associated with the MTEL is the variation in the effective local mass transfer across the electrode surface. The leading edge of the electrode exhibits a significantly enhanced local masstransfer coefficient due to the immediate contact with the bulk solution. The local mass-transfer coefficient decreases to a constant value with the development of the diffusion boundary layer. Variations in the average mass-transfer coefficient $\left(\mathrm{k}_{\mathrm{av}}\right)$ as a function of the distance (L) from the leading edge of an active electrode, in the flow direction, can be determined from Equation (4). ${ }^{13-15}$ The derivation of Equation (4) is based on the fundamental relationship between the developing mass transfer and the universal velocity profile in the viscous boundary layer and is essentially independent of the test geometry: ${ }^{16}$

\footnotetext{
(1) UNS numbers are listed in Metals and Alloys in the Unified Numbering System, published by the Society of Automotive Engineers (SAE International) and cosponsored by ASTM International.
}

$$
\mathrm{k}_{\mathrm{av}}=0.81\left(\frac{\tau_{\mathrm{w}}}{\rho}\right)^{1 / 3}\left(\frac{\nu}{\mathrm{L}}\right)^{1 / 3} \mathrm{Sc}^{-2 / 3}
$$

Equation (4) highlights a very important aspect in the comparison of hydrodynamics produced in a laboratory apparatus and the field application. The relationships presented in Equations (1) through (3) describe the situation of a fully developed mass transfer. Application of Equation (3) to estimate the mass transfer in a fully developed pipe flow assumes a continuous and homogeneous mass-transfer surface where there are no variations in scale composition, continuity, or surface roughness. In reality, these conditions can never be achieved and the assumption of a fully developed mass transfer is purely hypothetical.

This study investigates the influence of the MTEL on the corrosion rate and the cathodic limiting current using the jet impingement technique. The results of the cathodic limiting current densities are compared to those determined using a flow loop ${ }^{14}$ to illustrate that although the jet impingement produces the same trend, the numerical relationships are somewhat different.

\section{EXPERIMENTAL PROCEDURES}

All tests were performed in a custom-made JIC constructed from Type 316L (UNS S31603) ${ }^{(1)}$ stainless steel. The hydrodynamics of the JIC were characterized with respect to the wall shear stress and mass transfer on the impinged surface by the limiting current technique using ferricyanide $\left(\left[\mathrm{Fe}(\mathrm{CN})_{6}\right]^{3-}\right) .{ }^{17}$ The exit of a 2-mm-diameter jet was positioned $10 \mathrm{~mm}$ from the impinged surface. The JIC incorporated a standard three-electrode arrangement for electrochemical measurements, comprising a C-276 (UNS N10276) pseudo-reference electrode, a carbon steel working electrode, and a platinum mesh counter electrode. Two unique working electrodes were machined from a carbon steel rod into 50-mm-long cylinders of $1-\mathrm{mm}$ and 3-mm thicknesses with a consistent 5.5-mm internal diameter. The electrodes were embedded into an epoxy resin and ground on the axial end using 1000-grit silicon carbide (SiC) paper to expose a ring with a surface area of $0.204 \mathrm{~cm}^{2}$ and $0.801 \mathrm{~cm}^{2}$, respectively.

A synthetic brine solution consisting of $30 \mathrm{~g} / \mathrm{L}$ sodium chloride $(\mathrm{NaCl})$ and $100 \mathrm{mg} / \mathrm{L}$ sodium bicarbonate $\left(\mathrm{NaHCO}_{3}\right)$ was used as a common non-scaling electrolyte. ${ }^{17-18}$ All tests were performed at $30^{\circ} \mathrm{C}$ with a $\mathrm{CO}_{2}$ partial pressure of 1.88 bar, equivalent to a dissolved $\mathrm{CO}_{2}$ concentration of $0.05 \mathrm{M}$. Test solutions were sparged with a high-purity carbon dioxide (oxygen $<5$ ppm), filtered through an in-line scrubber system comprising a high-capacity oxygen scrubber and a self-indicating oxygen trap to remove low levels of oxygen in the source gas. Dissolved oxygen concentrations were monitored using a dissolved oxygen meter 
and were maintained below $0.5 \mathrm{ppb}$. The meter was calibrated in air according to the manufacturer's recommendations and cross checked against certified gas mixtures. At atmospheric pressures, dissolved oxygen tubes with an analytical range of 0 to $20 \mathrm{ppb}$ were used as an additional verification.

Corrosion rates were determined by electrochemical impedance spectroscopy (EIS) following a 30-min equilibration period. ${ }^{19-21}$ EIS spectra were obtained using a sinusoidal excitation potential of $5 \mathrm{mV}_{\mathrm{rms}}$ over a frequency range from $10^{5} \mathrm{~Hz}$ to $10^{-1} \mathrm{~Hz}$. The EIS system comprised a frequency response analyzer connected to a potentiostat that was controlled using appropriate software. Cathodic limiting current densities were determined by polarizing the working electrode in a cathodic direction $250 \mathrm{mV}$ from the open-circuit potential using a scan rate of $1 \mathrm{mV} / \mathrm{s}$.

\section{RESULTS AND DISCUSSION}

The JIC was used to investigate the effect of the MTEL on the corrosion rate of carbon steel in a $\mathrm{CO}_{2}-$ saturated brine solution at $30^{\circ} \mathrm{C}$. The investigation was performed using two-ring electrodes with differing lengths in the flow direction of $1 \mathrm{~mm}$ and $3 \mathrm{~mm}$. Figure 2 illustrates the design and placement of the tworing electrodes in the flow field of the JIC.

The placement of both electrodes in the transition region was chosen to reduce any differences caused by the changing flow profile on the impinged surface. Tests were conducted over a range of flow velocities to study the effects of increased flow velocity on the MTEL and the corrosion rate. Increasing the flow velocity effectively thins the diffusion boundary layer, through an increased turbulent mass transfer in the bulk solution, and significantly reduces the MTEL.

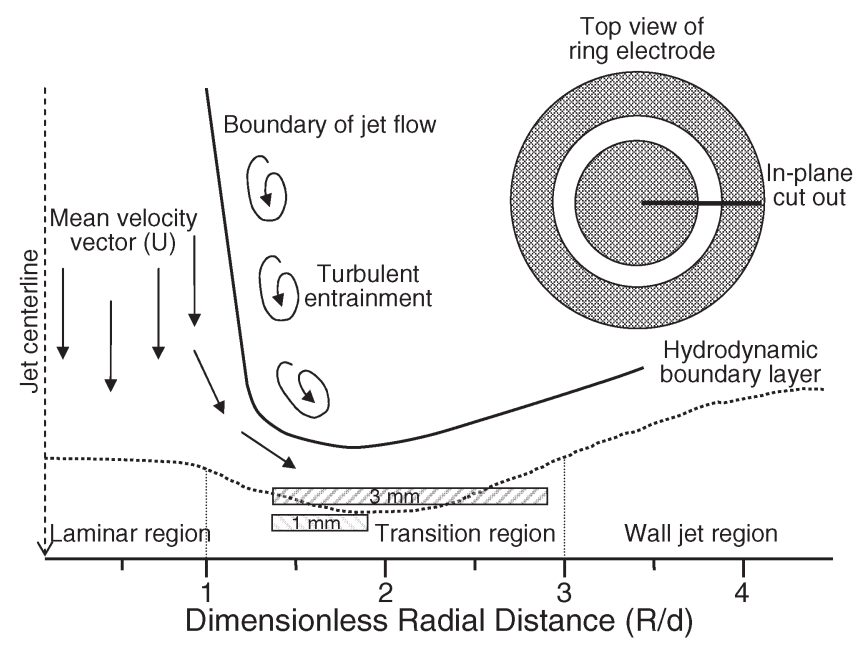

FIGURE 2. Illustration of the design and placement of the two-ring electrodes in the flow field of the JIC.

The corrosion data is correlated with respect to the flow velocity, in terms of the Reynolds number (Re), and the average rate of mass transfer to the electrodes in terms of the dimensionless Sherwood number $\mathbf{~} \mathrm{Sh}=$ $\mathrm{kd} / \mathrm{D}$ ), where $\mathrm{d}$ is the hydrodynamic diameter (i.e., jet diameter $2 \mathrm{~mm}), \mathrm{k}$ is the mass transfer $(\mathrm{m} / \mathrm{s})$, and $\mathrm{D}$ is the diffusion coefficient $\left(\mathrm{m}^{2} / \mathrm{s}\right)$.

Figure 3 presents the relationship between the corrosion rate and the flow velocity determined from the two electrodes in terms of the Reynolds number (Re). The Reynolds number represents the dimensionless flow velocity by normalization with the fluid properties of density $(\rho)$ and dynamic viscosity $(\mu)$, and the principle hydrodynamic parameter, which in this case is the jet diameter (d). Ultimately, in this series of tests, variations in the Reynolds number are directly

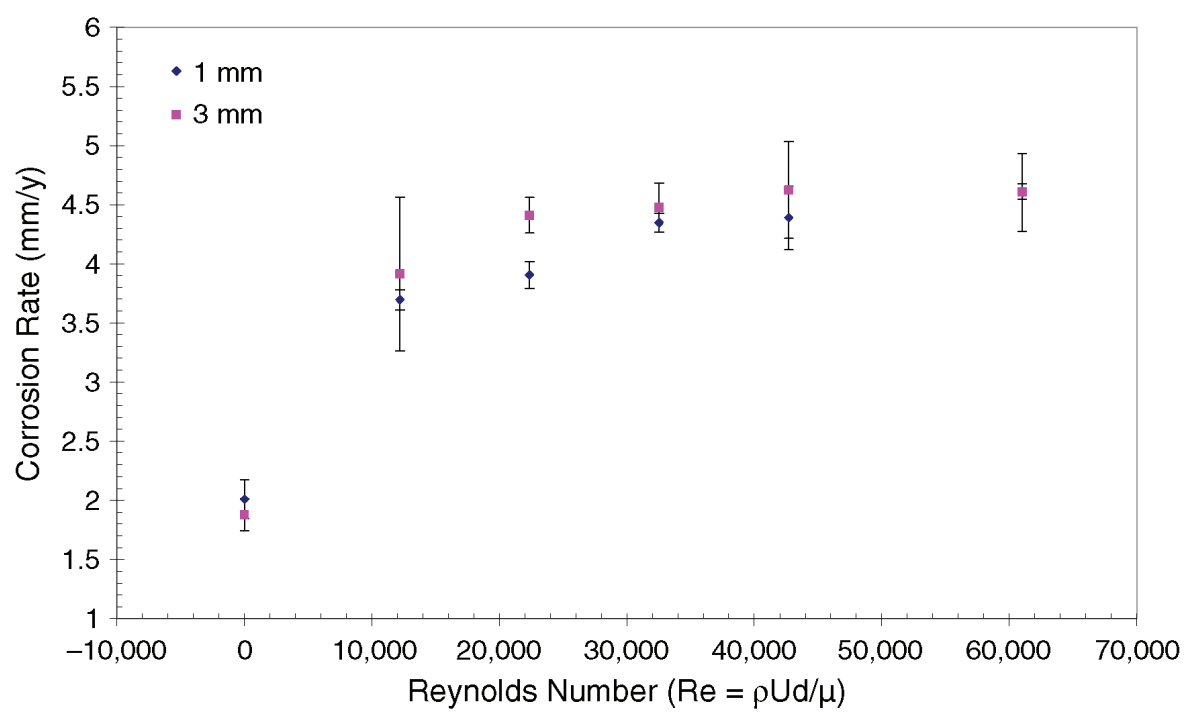

FIGURE 3. Effect of flow velocity on the rate of $\mathrm{CO}_{2}$ corrosion of mild steel determined using the jet impingement cell. 1-mm and 3-mm ring electrodes (Grade 1020); $30^{\circ} \mathrm{C}$; standard brine solution; $\left[\mathrm{CO}_{2}\right]=0.05 \mathrm{M}$. 
proportional to the flow velocity. The data from two different-sized electrodes illustrate almost identical relationships with increasing flow velocity. Under stagnant conditions the determined corrosion rates $(2.0 \mathrm{~mm} / \mathrm{y}$ and $1.9 \mathrm{~mm} / \mathrm{y}$ from the $1-\mathrm{mm}$ and $3-\mathrm{mm}$ electrodes, respectively) resemble the rate calculated from the classic de Waard and Milliams equation (ca. $\sim 2.11 \mathrm{~mm} / \mathrm{y}){ }^{22}$ This does not necessarily indicate that the corrosion rate measured under dynamic conditions is reasonable but that both electrodes are behaving in a manner that is consistent with that predicted for $\mathrm{CO}_{2}$ corrosion. Under dynamic conditions, the measured corrosion rates $(\sim 4.5 \mathrm{~mm} / \mathrm{y})$ are comparable to those measured by Gulbrandsen and Granå ${ }^{23}$ $(\sim 3 \mathrm{~mm} / \mathrm{y}$ to $4 \mathrm{~mm} / \mathrm{y})$ using a jet impingement cell with a brine solution saturated with $\mathrm{CO}_{2}$ at 1 bar and a temperature of $40^{\circ} \mathrm{C}$. Upon application of flow $(\operatorname{Re} 12,204)$, the corrosion rate rapidly increases to a rate almost double that determined under stagnant conditions. Further increases in flow velocity were found to increase the resulting corrosion rates only marginally, illustrating minimal further dependence on the flow velocity. The occurrence of this limiting plateau with increasing flow velocity is consistent with the documented literature ${ }^{24-25}$ and can be anticipated from the conventional mixed activation-mass transfer (concentration polarization) control of $\mathrm{CO}_{2}$ corrosion. ${ }^{22,26}$ In accordance with this mechanism, there is a critical mass transfer above which the corrosion rate will be dominated by an activation process and will be independent of the flow velocity.

A review of Figure 3 suggests that the 3-mm electrode reaches a distinct plateau in the corrosion rate at a lower Reynolds number than the 1-mm electrode. The corrosion rate on the 3-mm electrode appears relatively constant above a Reynolds number of 22,304 in comparison to the 1-mm electrode, which appears to become constant above 32,544 . The similarity in the trends between the two different-sized electrodes presented in Figure 3 suggests that the jet exit velocity is not an appropriate variable to analyze the effect of the MTEL on the corrosion rate. This can be anticipated on the basis that as a proportion of the surface area, the longer electrode in the flow direction (i.e., $3 \mathrm{~mm}$ electrode) will be in contact with less of the bulk fluid as the reactants are consumed and the diffusion boundary layer is developed over a greater distance than on the shorter electrode at the same jet exit velocity. The purpose of illustrating this result is to show that a comparison of corrosion rates based on the flow velocity can be misleading. It should be recognized that the average shear stress and mass transfer to the longer electrode is significantly less than for the shorter electrode at the same jet velocity.

The effect of the MTEL on the corrosion rate is more appropriately represented as a function of the average mass transfer $\left(\mathrm{k}_{\mathrm{av}}\right)$ to the electrode surface. The average mass transfer to the $1-\mathrm{mm}$ and $3-\mathrm{mm}$ electrodes was calculated from limiting current measurements for ferricyanide reduction on microelectrodes. This yields the shear stress over the impinged surface that enabled the calculation of the $\mathrm{k}_{\mathrm{av}}$ using Equation (4). ${ }^{17}$ The limiting current density from the ferricyanide reduction curves was used to calculate the average rate of mass transfer of $\mathrm{H}^{+}$and carbonic acid $\left(\mathrm{H}_{2} \mathrm{CO}_{3}\right)$ to the two electrodes over the studied range of flow velocities. The average rate of mass transfer to the shorter electrode is always greater than that to the longer electrode at the same jet exit velocity due to the MTEL phenomenon. A greater proportion of the surface area of the shorter electrode is exposed to the bulk reactant concentration before the concentration is decreased by the surface reaction and the diffusion boundary layer begins to form. For example, at a jet exit velocity of $26 \mathrm{~m} / \mathrm{s}$, the $1-\mathrm{mm}$ electrode has a mass transfer of $4.567 \times 10^{-3} \mathrm{~m} / \mathrm{s}$ with an average diffusion boundary layer thickness $\left(\delta_{\mathrm{D}}\right)$ of $2.07 \mu \mathrm{m}$ from the relationship $\left(\delta_{\mathrm{D}}=\mathrm{D} / \mathrm{k}_{\mathrm{av}}\right.$, where $\mathrm{D}=$ $\left.9.46 \times 10^{-9} \mathrm{~m}^{2} \mathrm{~s}^{-1}\right)$. The average mass transfer to the $3-\mathrm{mm}$ electrode is $3.067 \times 10^{-3} \mathrm{~m} / \mathrm{s}$ with an average diffusion boundary layer thickness of $3.08 \mu \mathrm{m}$.

It is conventionally recognized that the wall shear stress and mass transfer are two interrelated hydrodynamic parameters that can influence the corrosion rate/mechanism through two completely different processes. The influence of the mass transfer is directly involved in the rate of chemical reactions, while the wall shear stress may indirectly affect the rate of corrosion through the physical disruption of scales and adherent layers. ${ }^{6}$ Under the test conditions used in this investigation, the probability of scaling is considered to be negligible and the influence of flow velocity on the corrosion rate can be simplified to a single parameter being the mass transfer. ${ }^{17,27-28}$ This assumption is reasonable since the effect of the wall shear stress on the corrosion rate is purely mechanical in nature, being related to the physical disruption of surface scales. In the absence of surface scales, this influence is negligible.

The relationship between the corrosion rate and the mass transfer to the two electrodes is presented in Figure 4 in terms of the Sherwood number (Sh), derived from the estimated rate of mass transfer of $\mathrm{H}^{+}$, hydrodynamic diameter of the jet $(\mathrm{d}=0.002 \mathrm{~m})$, and diffusion coefficient $\left(\mathrm{D}=9.46 \times 10^{-9} \mathrm{~m}^{2} \mathrm{~s}^{-1}\right.$ ) of $\mathrm{H}^{+}$. From this graph, it is apparent that there are significant differences in the corrosion behavior of the two electrodes. Converse to the anticipated relationship, the corrosion rate does not exhibit a direct proportionality with the mass transfer. In contrast, the corrosion rate at the $3-\mathrm{mm}$ electrode is statistically greater than that at the shorter 1-mm electrode at a considerably lower mass transfer. This result concurs with the findings of Mendoza-Flores and Turgoose in their study of the limiting cathodic current density with increasing electrode lengths in pipe geometry. ${ }^{14}$ 


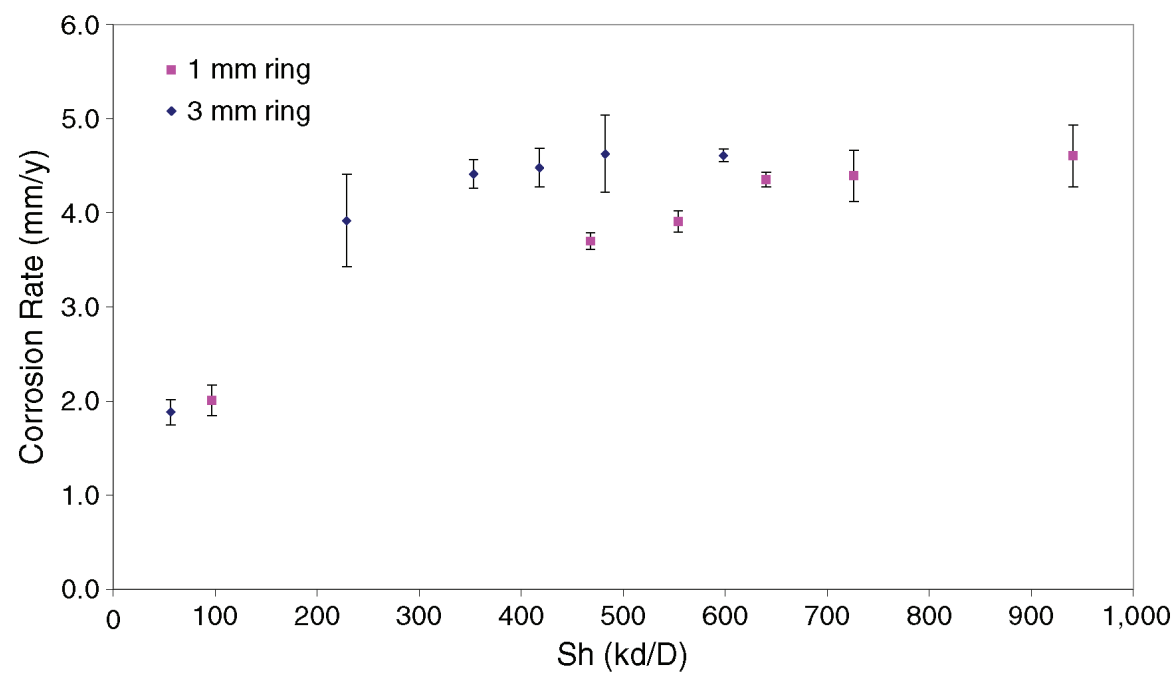

FIGURE 4. Comparison of the effect of electrode length and average mass transfer on the rate of $\mathrm{CO}_{2}$ corrosion of mild steel. 1-mm and 3-mm ring electrodes (Grade 1020); $30^{\circ} \mathrm{C}$; standard brine solution; $\left[\mathrm{CO}_{2}\right]=0.05 \mathrm{M}$.

It is evident that the corrosion rate illustrated in Figure 4 does not exhibit a simple direct relationship with the mass transfer. A clear distinction between these two electrodes is the state of development of the diffusion boundary layer as a consequence of the MTEL. A greater proportion of the diffusion boundary layer over the shorter 1-mm electrode will be less developed than that over the longer 3-mm electrode. Ultimately, this entails a greater average mass transfer to the shorter electrode and therefore thinner average diffusion boundary layer (e.g., $[1 \mathrm{~mm}] \delta_{\mathrm{D}}=2.07 \mu \mathrm{m}$ compared to $\left.[3 \mathrm{~mm}] \delta_{\mathrm{D}}=3.08 \mu \mathrm{m}\right)$. The primary consequence of the different states of development of the diffusion boundary layer is the subsequent variation in the interfacial chemistry. Evidently, this variation, which must be a product of the surface reaction, has a greater influence on the corrosion rate than the direct mass transfer of bulk reactants to the surface. Conceivably, alteration of the interfacial $\mathrm{pH}$ by the cathodic reactions and the $\mathrm{CO}_{2}$ equilibria is the most probable change that could influence the corrosion rate.

At the equilibrium corrosion potential where the corrosion rate becomes independent of the flow velocity, it may be argued that the interfacial concentration is not significantly different from the bulk. Under this condition, the corrosion rates at both electrodes are expected to be similar and independent of the rate of mass transfer and to this extent the influence of the MTEL. The influence of the MTEL can be explored further by driving the cathodic reaction with an applied potential more negative than the open-circuit potential, such that the cathodic current becomes limited by the rate of mass transfer. At sufficiently high cathodic overpotentials where the cathodic limiting currents are observed, there can be no doubt that the surface concentration is significantly different to the bulk and the influence of the MTEL can be exacerbated.

Figure 5 shows the cathodic limiting current densities at various rates of mass transfer to the $1-\mathrm{mm}$ and 3-mm electrodes and compares the data with a theoretical calculation of the mass-transfer-limited current density. The theoretical calculation is based on the total current density derived from the mass transfer of the available cathodic reactant concentration (i.e., $\mathrm{pH}=4.5$ and $\left[\mathrm{H}_{2} \mathrm{CO}_{3}\right]=0.0575 \mathrm{~mol} / \mathrm{m}^{3}$ ).

The plotted data illustrates the expected linear relationship with respect to the mass transfer. Coincidently, the results from the 1-mm electrode resemble the theoretically calculated relationship. In contrast, the results from the 3-mm electrode show a greater dependence of the cathodic limiting current on the rate of mass transfer. This result concurs with the data presented from the analysis of the corrosion rate and supports the notion that a change in the interfacial chemistry causes an increase in the apparent concentration/availability of a cathodic reactant.

Mendoza-Flores and Turgoose ${ }^{14}$ published comparable results to that illustrated in Figure 5 from the measurement of cathodic limiting current densities using two dissimilar electrode lengths $(1 \mathrm{~mm}$ and $5 \mathrm{~mm}$ ) in a flow loop tester. The tests were performed at $50^{\circ} \mathrm{C}$ in a $3.5 \% \mathrm{NaCl}$ solution saturated with a $\mathrm{CO}_{2}$ partial pressure at 1 bar and $\mathrm{pH} 4$. Analysis of their results show that the gradients of linear fits to the data were approximately $8,000 \mathrm{~A} / \mathrm{m} \cdot \mathrm{s}$ and $10,000 \mathrm{~A} / \mathrm{m} \cdot \mathrm{s}$ for the 1-mm and 5-mm electrodes, respectively. In contrast, the results shown here depict values of $5,000 \mathrm{~A} / \mathrm{m} \cdot \mathrm{s}$ and $8,000 \mathrm{~A} / \mathrm{m} \cdot \mathrm{s}$ for the $1-\mathrm{mm}$ and 3-mm electrodes, respectively. The differences in the linear relationships may be a consequence of variations in the test conditions and the significantly greater mass transfer and flow velocity analyzed in 


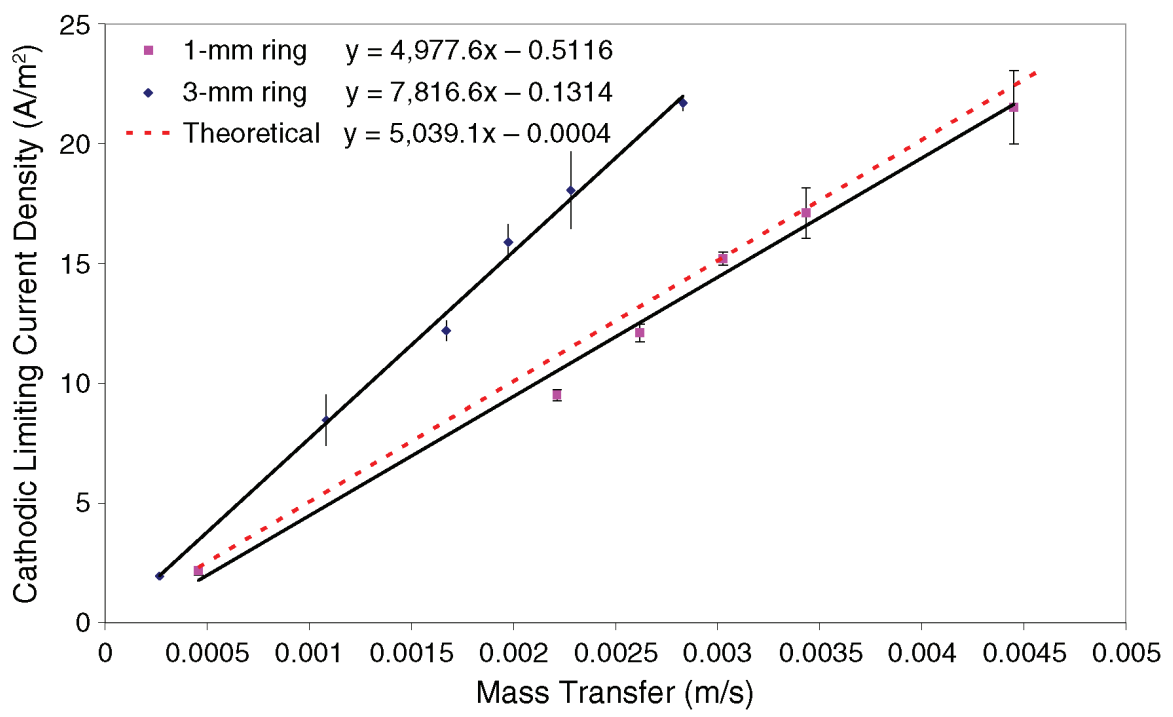

FIGURE 5. Influence of the electrode length on the cathodic limiting current densities and the calculated mass-transferlimited current density. 1- $\mathrm{mm}$ and 3- $\mathrm{mm}$ ring electrodes (Grade 1020); 30 $\mathrm{C}$; standard brine solution; $\left[\mathrm{CO}_{2}\right]=0.05 \mathrm{M}$.

the jet impingement in comparison to the flow loop tester. It is clear nonetheless that the general trend (i.e., greater dependence with increasing electrode length in the flow direction) in both geometries is the same. It may be concluded from the comparison that although trends in the corrosion rate are internally consistent, actual corrosion rates are likely to be different.

A possible explanation of the observed influence of the MTEL on the flow relationship of $\mathrm{CO}_{2}$ corrosion may be theorized through the increased rate of hydration of dissolved $\mathrm{CO}_{2}$ at higher $\mathrm{pH}$. According to the current theory of $\mathrm{CO}_{2}$ corrosion, it is believed that at temperatures below $50^{\circ} \mathrm{C}$ the corrosion rate is limited by the rate of hydration of dissolved $\mathrm{CO}_{2}$, either through a homogeneous ${ }^{29-30}$ or heterogeneous ${ }^{26,31}$ reaction mechanism. A plausible pathway to achieve higher rates of hydration, and therefore a greater corrosion rate, is the involvement of $\mathrm{OH}^{-}$at the interface. An increase in the solution $\mathrm{pH}$ is known to catalyze the rate of hydration $\left(\mathrm{k}_{\mathrm{h}}\right)$ of dissolved $\mathrm{CO}_{2}$ by creating a parallel hydration pathway through the direct nucleophilic attack by $\mathrm{OH}^{-}$. In the presence of hydroxide, the Gibbs free energy of activation for the hydration of $\mathrm{CO}_{2}$ is reduced from $82 \mathrm{~kJ} / \mathrm{mol}$ to $51 \mathrm{~kJ} / \mathrm{mol}^{32-33}$ Rates of hydration as high as $8,500 \mathrm{~s}^{-1}$ have been observed at $\mathrm{pH} 14$ at $25^{\circ} \mathrm{C}$, in comparison with the $\mathrm{pH}$-independent hydration by water of $0.03 \mathrm{~s}^{-1}$. Since the local $\mathrm{pH}$ at the interface would be greater than the bulk in the diffusion boundary layer as a result of the consumption of $\mathrm{H}^{+}$, it follows that the overall rate of hydration of dissolved $\mathrm{CO}_{2}$ would also be greater. The more developed the diffusion boundary layer, the thicker the interfacial region, where the solution $\mathrm{pH}$ is greater than the bulk, providing an increased residence time for the dissolved $\mathrm{CO}_{2}$ to react within the diffusion layer. An increased rate of production of $\mathrm{H}_{2} \mathrm{CO}_{3}$ would correspond to an increased rate of corrosion in a more developed diffusion boundary layer.

\section{CONCLUSIONS}

* The jet impingement technique has been used to evaluate the flow dependence of $\mathrm{CO}_{2}$ corrosion in a non-scaling brine solution at $30^{\circ} \mathrm{C}$ with a $\mathrm{CO}_{2}$ partial pressure of 1.88 bar. The results illustrate an initial dependence on the flow velocity up to a Reynolds number of 22,304 , beyond which the corrosion rate is essentially independent of flow.

* A distinct contrast is observed in the mass-transfer dependence of the corrosion rate between electrodes of different lengths in the flow direction. The disparity is attributed to the state of development of the diffusion boundary layer over the reactively corroding electrode. It is evident that the corrosion rate is greater at electrodes with a more developed diffusion boundary layer at a lower average mass transfer. The state of development of the diffusion boundary layer can be explained by the MTEL where the immediate leading edge of electrodes in flowing solutions are exposed to the unaltered bulk concentration of solution reactants. The longer electrode in the flow direction has a greater distance for the surface reactants to be consumed and the diffusion boundary layer to form. Ultimately, this means that the difference in the surface and bulk concentration of reactants is more pronounced over a greater proportion of the electrode surface area with increasing length in the flow direction.

* Analysis of the cathodic limiting current concurs with the observed trend in the measured corrosion rates and supports the conclusion that the MTEL has a significant effect on the mechanism of $\mathrm{CO}_{2}$ corro- 
sion. Plots show that the mass-transfer-limited current density is greater in magnitude at a lower average mass transfer at the longer 3-mm electrode in comparison to the 1-mm electrode with pronounced dependency on the rate of mass transfer.

* The observed influence of the MTEL is considered to be linked to variations in the interfacial chemistry which may promote the corrosion mechanism. A plausible explanation for the effect of the MTEL on the corrosion reaction is the variation in the surface $\mathrm{pH}$ by the reduction of $\mathrm{H}^{+}$and carbonic acid. Any increase in $\mathrm{pH}$ will stimulate a concomitant hydration pathway for dissolved $\mathrm{CO}_{2}$, via the direct nucleophilic attack of $\mathrm{OH}^{-}$, and thus increase the rate of production of carbonic acid.

* Comparison of active electrodes of differing lengths in the flow direction illustrated the significant influence of the developing diffusion boundary layer on the rate of $\mathrm{CO}_{2}$ corrosion. The dependence on the developing diffusion boundary provides a strong argument for the inconsistency in corrosion behavior observed using different electrode geometries and test apparatuses. A resounding conclusion from this study is the criticality of the MTEL to the correlation between various laboratory geometries and field investigations into $\mathrm{CO}_{2}$ corrosion. Needless to say, this does not imply that a unique state of development of the diffusion boundary layer will offer the best correlation with all field conditions. Flow disruptions, flow velocity, local turbulence, scale composition and uniformity, and fluid composition are some factors that will directly influence the development and chemical nature of the diffusion boundary layer.

\section{REFERENCES}

1. NACE Publication 5A195, "State-of-the-Art Report on ControlledFlow Laboratory Corrosion Tests” (Houston, TX: NACE International, 1995).

2. ASTM Standard G170-01a, "Evaluating and Qualifying Oilfield and Refinery Corrosion Inhibitors in the Laboratory" (West Conshohocken, PA: ASTM International, 2002).

3. K.D. Efird, "Experimental Correlation of Laboratory Results to Field Applications for Flow-Induced Corrosion in Sweet Production," 12th Int. Corros. Congr.: Corrosion Control for Low-Cost Reliability Conf., paper no. 194 (Houston, TX: NACE, 1993).

4. D.C. Silverman, Corrosion 44, 1 (1988): p. 42.

5. D.C. Silverman, Corrosion 60, 11 (2004): p. 1,003.

6. K.D. Efird, E.J. Wright, J.A. Boros, T.G. Hailey, Corrosion 49, 12 (1993): p. 992

7. S. Nešić, G.T. Solvi, J. Enerhaug, "Comparison of the Rotating Cylinder and Pipe Flow Tests for Flow-Sensitive Carbon Dioxide Corrosion," in CORROSION/95, paper no. 95130 (Houston, TX: NACE, 1995).
8. S. Nešić, G.T. Solvi, S. Skjerve, "Rotating Cylinder vs. Loop Testing of Inhibitors for $\mathrm{CO}_{2}$ Corrosion," 8th European Symp. on Corrosion Inhibitors, vol. 10 (Ann. Univ. Ferrara, Sez. 5 Suppl., 1995).

9. S. Nešić, G.T. Solvi, S. Skjerve, Br. Corros. J. 32 (1997): p. 269.

10. S. Papavinasam, R.W. Revie, M. Attard, A. Demoz, K. Michaelian, Corrosion 59, 10 (2003): p. 897.

11. S. Papavinasam, R.W. Revie, M. Attard, A. Demoz, H. Sun, J.C. Donini, K. Michaelian, "Inhibitor Selection for Internal Corrosion Control of Pipelines: 1. Laboratory Methodologies," CORROSION/ 99, paper no. 99001 (Houston, TX: NACE, 1999).

12. D.C. Silverman, Corrosion 44 (1987): p. 42.

13. S. Turgoose, J.L. Dawson, J.W. Palmer, T. Rizk, M.R. Reda, J.N. Alhajji, "Boundary Layer Effects in Turbulent Flow Testing Determination of Mass-Transfer Coefficient of a Modified Corrosion Cell Which Simulates Impingement Attack," CORROSION/95, paper no. 95112 (Houston, TX: NACE, 1995).

14. J. Mendoza-Flores, S. Turgoose, "Influence of Electrode Length on the Measurement of Cathodic Kinetics of Steel Corrosion in $\mathrm{CO}_{2}$ Containing Solutions, Under Turbulent Flow Conditions," CORROSION/2002, paper no. 02490 (Houston, TX: NACE, 2002).

15. K.G. Jordan, P.R. Rhodes, "Corrosion of Carbon Steel by $\mathrm{CO}_{2}$ Solutions: The Role of Fluid Flow," CORROSION/95, paper no. 95125 (Houston, TX: NACE, 1995).

16. T.J. Hanratty, J.A. Campbell, eds., "Measurement of Wall Shear Stress," in Fluid Mechanics Measurements, ed. R.J. Goldstein (New York, NY: Hemisphere Publishing Corp., 1983).

17. D.A. John, "Mechanism of Carbon Dioxide Corrosion and Inhibition Under High Flow: A Jet Impingement Study" (PhD thesis [Applied Chemistry], Curtin University of Technology, 2006), p 253.

18. D.A. John, A. Blom, S. Bailey, A. Nelson, J. Schulz, R. De Marco, B. Kinsella, Phys. Rev. B: Condens. Matter 385-386 (2006): p. 924.

19. B. Kinsella, Y.J. Tan, S. Bailey, Corrosion 54, 10 (1998): p. 835.

20. I.M. Ritchie, S. Bailey, R. Woods, Adv. Colloid Interface Sci. 80 (1999): p. 183.

21. S. Bailey, Y.J. Tan, B. Kinsella, Br. Corros. J. 32 (1997): p. 49.

22. C. de Waard, D.E. Milliams, Corrosion 31, 5 (1975): p. 177.

23. E. Gulbrandsen, A. Granå, Corrosion 63, 11 (2007): p. 1,009.

24. E. Eriksrud, T. Sontvedt, "Effect of Flow on $\mathrm{CO}_{2}$ Corrosion Rates in Real and Synthetic Formation Waters," CORROSION/1983, paper no. 83044 (Houston, TX: NACE, 1983).

25. C. de Waard, U. Lotz, A. Dugstad, "Influence of Flow Velocity on $\mathrm{CO}_{2}$ Corrosion: A Semi-Empirical Model," CORROSION/95, paper no. 95128 (Houston, TX: NACE, 1995).

26. G. Schmitt, "Fundamental Aspects of $\mathrm{CO}_{2}$ Corrosion," CORROSION/83, paper no. 83043 (Houston, TX: NACE, 1983).

27. D. John, S. Bailey, R. De Marco, B. Kinsella, "Flow Dependence of Carbon Dioxide Corrosion Rates and the Interference of Trace Dissolved Oxygen," CORROSION/2007, paper no. 07315 (Houston, TX: NACE, 2007).

28. D. John, B. Kinsella, R. DeMarco, S. Bailey, "A Mechanistic Approach to the Effect of Flow on Carbon Dioxide Corrosion," Corrosion and Prevention, paper no. 81 (Clayton, Australia: Australasian Corrosion Association, 2004).

29. S. Nešić, B.F.M. Pots, J. Postlethwaite, N. Thevenot, J. Corros. Sci. Eng. 1, paper no. 3 (1995): p. 1.

30. S. Nešić, N. Thevenot, J.-L. Crolet, D.M. Drazic, "Electrochemical Properties of Iron Dissolution in the Presence of $\mathrm{CO}_{2}$-Basics Revisited," CORROSION/96, paper no. 96003 (Houston, TX: NACE, 1996).

31. G. Schmitt, B. Rothmann, Werkst. Korros. 28 (1977): p. 816.

32. A.V. Nemukhin, I.A. Topol, B.L. Grigorenko, S.K. Burt, J. Phys. Chem. B 106 (2002): p. 1,734.

33. J.P. Guthrie, Can. J. Chem. 77 (1999): p. 934. 